\title{
Establishment of Economic Thresholds for Olive Moth, Prays oleae (Bern.) in Tras-Os-Montes Region
}

\author{
A. Bento \\ Escola Superior Agraria de Bragança, \\ Quinta Sta. Apolònia, \\ 5301-855 Bragança, Portugal \\ bento@ipb.pt
}

\author{
L. Torres \\ Universidade Tràs-os-Montes e Alto Douro, \\ Quinta de Prados, 5000-911 Vila Real \\ Portugal, \\ ltorres@utad.pt
}

Keywords: Integrated pest management, olive, Prays oleae, flower generation, crop loss assessment

\begin{abstract}
A mathematical model is presented which aims to establish the economic thresholds for the flower generation of olive moth, Prays oleae (Bern.) in Tràs-osMontes (north-eastern Portugal). The model is based on observations taken between 1993 and 1998, on olives of the oil variety Cobrançosa, grown under rain-fed conditions and without pesticide treatments for several years. It takes into account factors such as cost and efficacy of spraying, environmental impact, expected yield, price and crop losses. According to this model the control of the pest is justified when the percent of flower infestation is between $4.0 \%$ and $6.0 \%$ during the years of intermediate and high expected yields, (i.e., about $2400 \mathrm{~kg} / \mathrm{ha}$ ) and between $8.0 \%$ and $11.0 \%$ in the years of lower expected yields (i.e. approximately $1000 \mathrm{~kg} / \mathrm{ha}$ ) for prices usually practised in the region.
\end{abstract}

\section{INTRODUCTION}

The olive moth, Prays oleae (Bern.) (Lepidoptera: Yponomeutidae), is one of the most serious pests of olives in the Mediterranean basin. This moth has three generations a year, attacking in succession flowers, fruits, and leaves. Usually the leaf generation does not affect very much the trees, but the damage by the flower and the fruit generations can often lead to significant losses (Bento, 1999). In response to the growing requirement for more efficient methods to control the pest, research is needed on economic thresholds (ET), which could enable the growers to determine the need for intervention with a specific control measure and to apply integrated systems for olive cropping. In this work a mathematical model is presented which aims to establish the economic thresholds for the flower (anthophagous) generation of $P$. oleae in the Tràs-os-Montes region (north-eastern Portugal).

\section{MATERIALS AND METHODS}

Experiments were carried out over a six year period, 1993 to 1998, in an olive grove near Mirandela, on olives of cv Cobrançosa about 40-year-old, grown under rainfed conditions and without pesticide treatments for several years. An initial and basic inequation was posed in order to calculate a population threshold which justify the need of a treatment, and will determine the minimum damage from which the application of such a treatment would be economically advantageous.

$$
\text { Cost of treatment }<\text { Losses }
$$

Each member of the inequation is defined by several factors, which are:

\section{Cost of Treatment}

The cost of the treatment $\left(\mathrm{C}_{\mathrm{t}}\right)$ was calculated on the assumption of using a cover spray from the ground of a commercial formulation of Bacillus thuringiensis (Berl.) or a chitin synthesis inhibitor. As the treatment does not completely eliminate the losses, an efficacy factor $(E)$ of $80 \%$ was added to this cost. Also an environmental factor $\left(E_{f}\right)$ that focuses on the impact of the treatment on the environment and the beneficial organisms was added to this cost, according to Hoyt and Tanigoshi (1983), Kapatos and Fletcher

Proc. $4^{\text {th }}$ IS on Olive Growing 
(1983), Pedigo et al. (1986) and Montiel and Madueno (1995a, 1995b). This factor, which depends on both the toxicity of the pesticide and the importance of the occurring beneficial organisms, was assumed to be equal to 1.1 when spraying with $B$. thuringiensis and to 1.4 when spraying with a chitin synthesis inhibitor.

Thus the expression cost of the treatment can be given as:

$$
\text { Cost of treatment }=\left(\mathrm{C}_{\mathrm{t}} / \mathrm{E}\right) \times \mathrm{E}_{\mathrm{f}}
$$

\section{Losses}

Losses were expressed as the percentage of attacked flower clusters, on the basis of the following parameters: (i) level of blossoming and rate of fruit formation; (ii) expected yield, which depends on several factors, such as climatic conditions, tree physiology and level of blossoming; (iii) market value per production unit.

The percentage of attacked flower clusters as well as the level of blossoming the rate of fruit formation and the expected yield, were estimated each year by analysing samples of 100 marked branches from 25 selected trees within the experimental orchard. Four branches per tree were considered, each with a minimum of 15 flower clusters and of lenght 20 to $30 \mathrm{~cm}$. The compensation in response to premature fruit drop was assumed to be equal to 0.9, according to Neueschwander et al. (1980). Three market values per production unit were used, the minimum, the medium and the maximum usually practised in the region.

Then, we try to explain $P$. oleae losses, from the percentage of attacked flower clusters and the average potential crop yield per tree, throughout the equation:

$$
\mathrm{Pj}=\left(\mathrm{a} \times \mathrm{P}_{\mathrm{a}}+\mathrm{b} \times \mathrm{P}_{\mathrm{p}}+\mathrm{c}\right)
$$

$\mathrm{Pj}$ - are losses per tree, including the compensation for increasing the weight of the remaining fruits in 10 percent;

$\mathrm{P}_{\mathrm{a}}$ - is the percentage of attacked flower clusters

$\mathrm{P}_{\mathrm{p}}$ - is the average potential crop yield

$\mathrm{a}, \mathrm{b}$ and $\mathrm{c}$ - are model coefficients

To express losses in monetary terms, we obtain

$$
\mathrm{Pj}=\left(\mathrm{a} \times \mathrm{P}_{\mathrm{a}}+\mathrm{b} \times \mathrm{P}_{\mathrm{p}}+\mathrm{c}\right) \times \mathrm{P}_{\mathrm{r}}
$$

$\mathrm{P}_{\mathrm{r}}$ - is the market value per production unit

Therefore, equation (1) becomes

$$
(\mathrm{Ct} / \mathrm{E}) \times \mathrm{E}_{\mathrm{f}}=\left(\mathrm{a} \times \mathrm{P}_{\mathrm{a}}+\mathrm{b} \times \mathrm{P}_{\mathrm{p}}+\mathrm{c}\right) \times \mathrm{P}_{\mathrm{r}}
$$

where $\mathrm{P}_{\mathrm{a}}$, represents the percentage of attacked flower clusters per tree that cause economic damage equal to the cost of the treatment, that is the economic threshold (ET). Then, by solving the equation (5) for ET, we obtain:

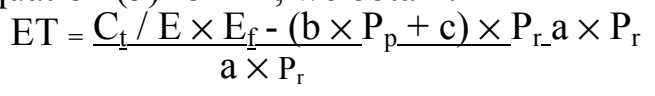

\section{RESULTS AND CONCLUSIONS}

Losses due to the flower generation of $P$. oleae, were highly variable between the studied years, ranging from $1.75 \mathrm{~kg}$ and $5.90 \mathrm{~kg}$ per tree, for a potential crop yield of respectively $14.02 \mathrm{~kg}$ and $56.16 \mathrm{~kg}$ per tree (Table 1). The percentage of attacked flower cluster was also highly variable, ranging from $1.76 \%$ and $12.96 \%$, exceeding most years the economic thresholds recommended in Spain of 5.0\% of attacked flower cluster. Of utmost importance on the expression of losses was the rate of fruit formation, which ranged from $3.23 \%$ and $15.86 \%$ (Table 1 ).

Analysis of the data showed that losses due to the flower generation of P.oleae on the observed samples were closely related with both, the percentage of attacked flower clusters and the potential crop yield per tree $\left(\mathrm{R}^{2}=96.4 \%\right)$ (Fig.1).

From the obtained data, it is possible to conclude that spraying is economically advantageous when the percent of flower infestation by $P$. oleae, is between $4.0 \%$ and $6.0 \%$ during the years of intermediate and high expected yields, i.e. about $2400 \mathrm{~kg} / \mathrm{ha}$, in relation with a high rate of fruit formation. In the years of lower expected yields, i.e. approximately $1000 \mathrm{~kg} / \mathrm{ha}$, it is economically advantageous to spray when the percent of 
flower infestation by the pest, is between $8.0 \%$ and $11.0 \%$ (Fig. 2 ).

The calculated economic thresholds revealed an variation of about $3.5 \%$, for the same potential crop yield, in accordance with the market value per production unit (Fig. 2). A more efficient use of these thresholds will depend on the possibility of predicting the rate of fruit formation, in relation with level of blossoming and the percentage of fertile flowers.

\section{ACKNOWLEDGEMENTS}

Research supported by the project PAMAF IED 2043

\section{Literature Cited}

Anonymous, 1997. Reglamento especìfico de producciòn integrada de olivar. Boja, 100, Sevilla, 28 de agosto 1997.

Bento, A. 1999. Contribuição para o estabelecimento de um programa de protecção integrada contra a traça da oliveira, Prays oleae (Bern.) em Tràs-os-Montes. Ph. D. Thesis, Universidade de Tràs-os-Montes e Alto Douro, Vila Real. 277pp.

Hoyt, S.C. and Tanigoshi, L.K. 1983. Economic injury levels for apple insect and mite pests. In Croft, B.A. and Hoyt S.C. (Ed) - Integrated management of insect pests of pome and stone fruits. Wiley, New York. Pp 203-218.

Kapatos, E. and Fletcher, B. 1983. Establishment of economic injury levels for olive infestation by Dacus oleae in Corfu. Entomologia Hellenica, 1: 37-45.

Montiel, A.B. and Madueño, C. 1995a. Cálculo prático del umbral de tratamiento para la mosca del olivo (Bactrocera oleae Gmel., Diptera: Tephritidae) en olivar de producción de aceite en Jaén. Boletin de Sanidad Vegetal Plagas, 21: 589-596.

Montiel, A.B. and Madueño, C. 1995b. Determinación del umbral de tratamiento para la mosca del olivo (Bactrocera oleae Gmel., Diptera: Tephritidae) en olivar destinado a la producciÛn de aceite. Boletin de Sanidad Vegetal Plagas, 21: 577-588.

Neusnschwander, P., Michelakis, S., Mikros, L. and Mathioudis, M. 1980. Compensation for early fruit drop caused by Dacus oleae (Gmel.) (Diptera, Tephritidae) due to an increase in weight and oil content of the remaining olives. Zeitschrift für Angewandte Entomologie, 89: 514-525.

Pedigo, L.P., Hutching, S.H. and Higley, L.G. 1986. Economic injury levels in theory and practice. Annual Review of Entomology, 31: 341-368.

\section{Tables}

Table 1. Parameters used for the establishment of economic thresholds for the flower generation for the olive moth, Prays oleae (Bern.) in Tràs-os-Montes. Mirandela, 1993 to 1998.

\begin{tabular}{|c|c|c|c|c|c|c|}
\hline \multirow{2}{*}{$\begin{array}{r}\text { Year } \\
\text { Parameter }\end{array}$} & & & & & & \\
\hline & 1993 & 1994 & 1996 & $1997^{(2)}$ & 1997 & 1998 \\
\hline Average flower clusters per tree & High & Low & High & Low & High & Medium \\
\hline$\%$ of attacked flower clusters ${ }^{(1)}$ & 12.51 & 1.76 & 12.96 & 12.64 & 6.64 & 4.68 \\
\hline $\begin{array}{l}\text { Average number of flower clusters per } \\
\text { tree }\end{array}$ & 22285 & 6790 & 27886 & 8096 & 31425 & 13141 \\
\hline Rate of fruit formation & 4.76 & 4.90 & 3.23 & 15.86 & 3.40 & 9.59 \\
\hline Average number fruit per tree & 18576 & 4105 & 13781 & 18233 & 19150 & 18249 \\
\hline Potential crop yield per tree $(\mathrm{kg})$ & 44.10 & 14.02 & 43.55 & 56.16 & 58.20 & 43.76 \\
\hline Losses due to $P$. oleae per tree $(\mathrm{kg})$ & 5.07 & 1.75 & 4.56 & 5.90 & 4.80 & 3.37 \\
\hline Average crop yield per tree $(\mathrm{kg})$ & 24.73 & 6.01 & 31.14 & 28.00 & 27.65 & 40.60 \\
\hline
\end{tabular}




\section{Figures}

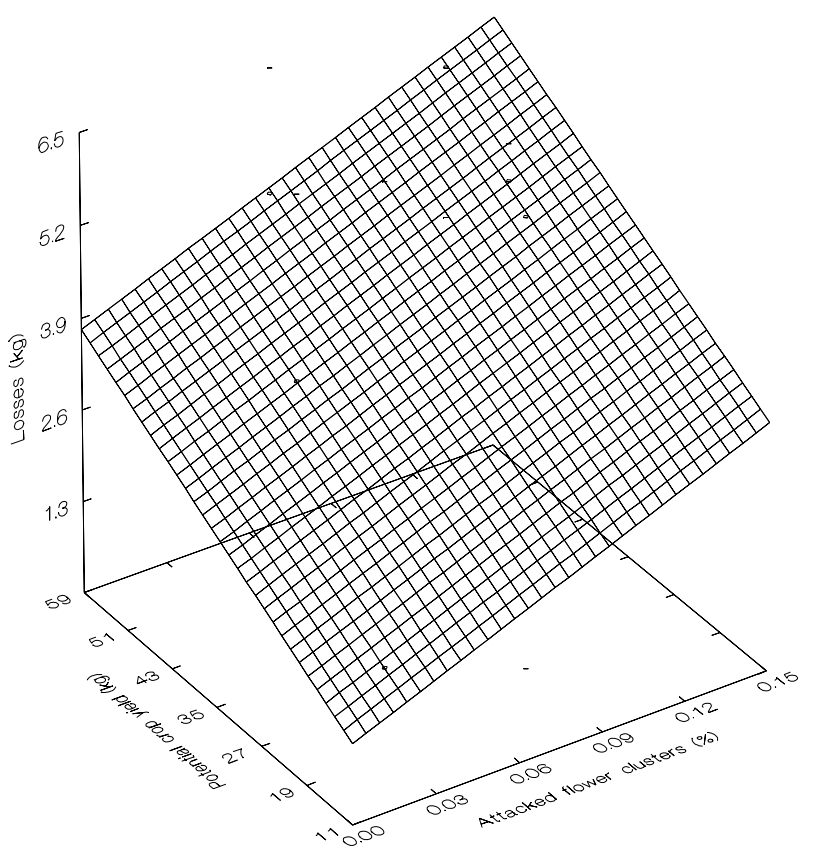

Losses $=0.158 \times \%$ attacked flower clusters

$+0.054 \times$ potential crop yield +0.550

$\mathrm{R}^{2}=96.4 \%$

$\mathrm{P}=0.007$

$\mathrm{N}=6$

Fig. 1. Relationship between losses due to the flower generation of $P$. oleae, the percentage of attacked flower clusters and the potential crop yield: multiple linear regression. Mirandela 1993 to 1998. 


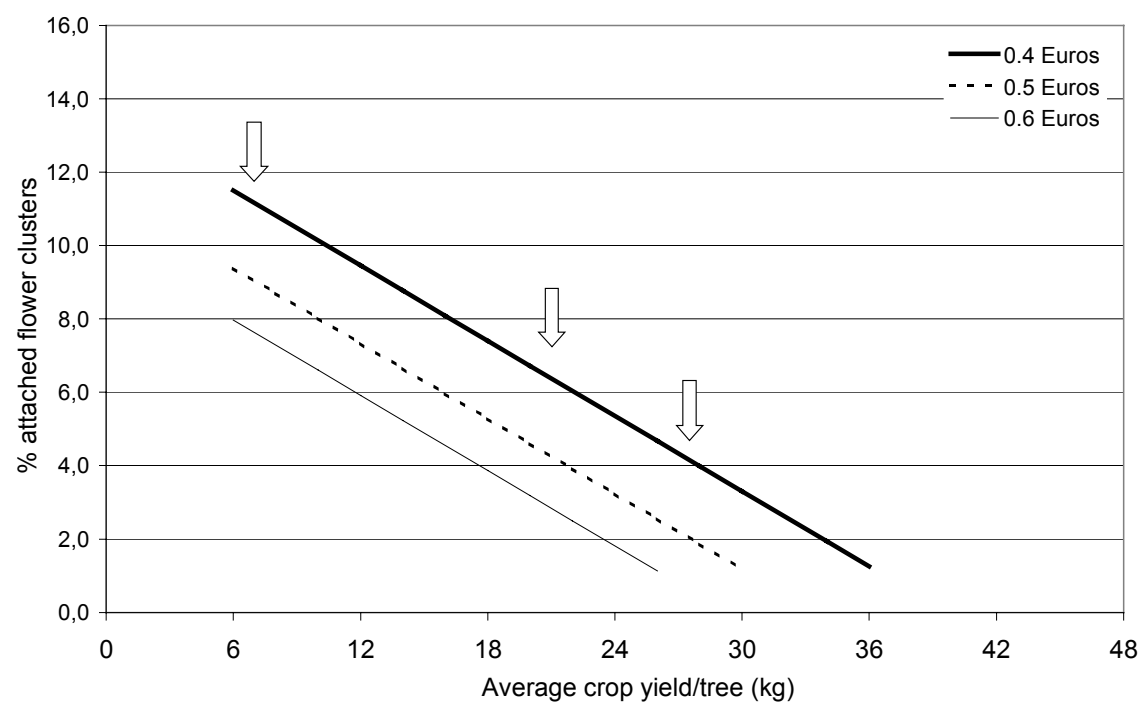

Fig. 2. Calculated economic thresholds for the flower generation for P. oleae in Tràs-osMontes for three market values per production unit. Mirandela, 1993 to 1998. 